NASA Contractor Report 189056

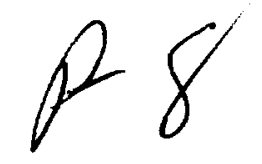

\title{
Evaluation of Kapton Pyrolysis, Arc Tracking, and Arc Propagation on the Space Station Freedom (SSF) Solar Array Flexible Current Carrier (FCC)
}

Thomas J. Stueber

Sverdrup Technology, Inc.

Lewis Research Center Group

Brook Park, Ohio

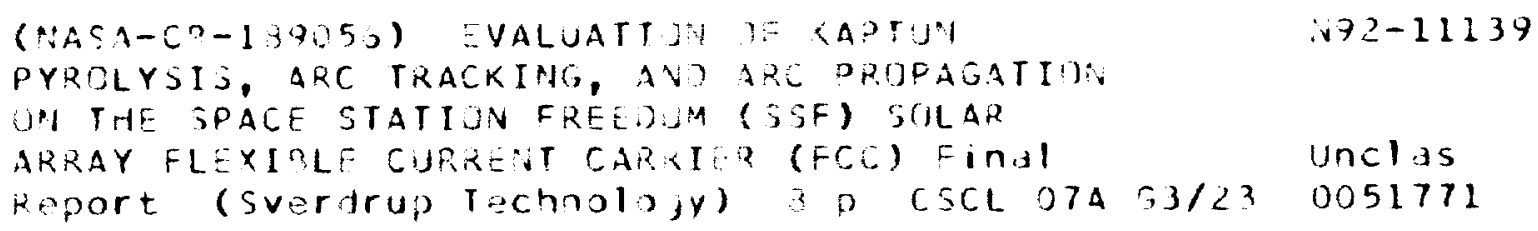

November 1991

Prepared for

Lewis Research Center

Under Contract NAS3-25266

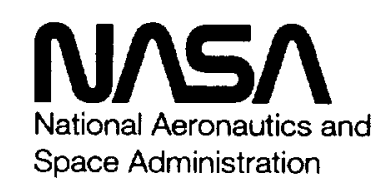


Trade names or manufacturers' names are used in this report for identification only. This usage does not constitute an of ficial endorsement, either expressed or implied, by the National Aeronautics and Space Administration. 
EVALUATION OF KAPTON PYROLYSIS. ARC TRACKING AND ARC PROPAGATION ON THE SPACE STATION FREEDOM (SSF) SOLAR ARRAY FLEXIBLE CURRENT CARRIER (FCC),

\author{
Thomas J. Stueber ${ }^{1}$ \\ Sverdrup Technology, Inc. \\ Lewis Research Center Group \\ Brook Park, Ohio 44142
}

\begin{abstract}
Recent studies conducted by the Air Force Materials Laboratory and Lockheed Missiles and Space Company involving the use of polyimide Kapton ${ }^{2}$ coated wires indicate that if a momentary electrical short circuit occurs between two wires, sufficient heating of the Kapton can occur to thermally char (pyrolyze) the Kapton $(1,2)$. Such charred Kapton has sufficient electrical conductivity to create an arc which tracks down the wires and possibly propagates to adjoining wires. These studies prompted an investigation to ascertain the likelihood of the Kapton pyrolysis, arc tracking and propagation phenomena, and the magni tude of destruction conceivably inflicted on Space Station Freedom's (SSF) Flexible Current Carrier (FCC) for the photovoltaic array. The geometric layout of the FCC, having a planar-type orfentation as opposed to bundles, may reduce the probability of sustaining an arc. An experimental investigation has been conducted to simulate conditions under which an arc can occur on the FCC of SSF, and the consequences of arc initiation.
\end{abstract}

\section{FCC TEST MATERIAL}

Tests were conducted on samples of FCC consisting of copper conductors between two layers of Kapton insulation, bonded together with a polyester adhesive. A sample FCC consisted of 4 channels, with each channel comprised of a wide (4.16 $\mathrm{mm} \times 0.15 \mathrm{~mm})$ copper return line between two thinner (2.46 mm x $0.15 \mathrm{~mm})$ copper supply lines as shown in figure 1. Each Kapton insulating layer was $0.083 \mathrm{~mm}$ thick. A defect site on the FCC consisted of a small area on one side of the FCC which exposed conductors to the environment. A typical defect site consisted of a partiallyexposed supply and return line. A defect site could naturally occur in low Earth orbit (LEO) due to micrometeoroid or debris impacts, coupled with atomic oxygen erosion.

\section{ENVIRONMENTAL EFFECTS}

\section{LEO Space Plasma}

Over a span of 15 years, the FCC located in LEO will sustain defect sites that expose the copper conductors to the LEO plasma environment. To determine whether Kapton pyrolysis could be initiated by Joule heating from positive-ion bombardment on the exposed, negatively-biased copper conductors, the FCC was tested in a lowdensity oxygen plasma environment.

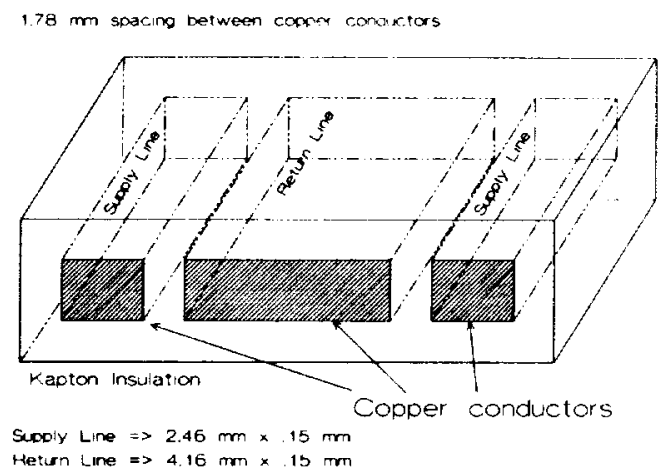

FIgure 1: One channel sample FCC

The directed atomic oxygen beam facility at NASA LeRC was utilized for the testing of an energized FCC within a low-density oxygen plasma environment. The plasma, generated with the use of a gridless ion source, and characterized with the use of a Langmuir probe, creates a more harsh environment than expected in LEO in terms of the ion density. As described in figure 2, a metal plasma potential reference cage was located approximately four feet outside of an $\mathrm{O}_{2}{ }^{+}$beam. The cage, located within the oxygen plasma emvironment, assumed the plasma potential. The FCC was mounted and electrically configured within the cage as shown in figure 3 . Therefore, the cage functioned as a reference point for biasing the FCC, with respect to the plasma potential. Figure 3 shows the FCC negatively biased 200 volts with respect to the plasma. The FCC could be electrical ly reconfigured for positive biasing with respect to the plasma by disconnecting the supply lines of the FCC from the cage and attaching the return line to the cage. The defect sites on three of the four Kapton-insulated FCC samples used for this low density oxygen plasma exposure test had only the blased copper conductor exposed to the plasma ervi ronment. Therefore, for the negatively-biased case, the return line was partially exposed (labeled in figure 3 as defect type $\# 1-\# 3$ ). A fourth type of defect, as labeled in figure 3 , had a $2 \mathrm{~mm}$ hole between one of the supply lines and the adjacent 


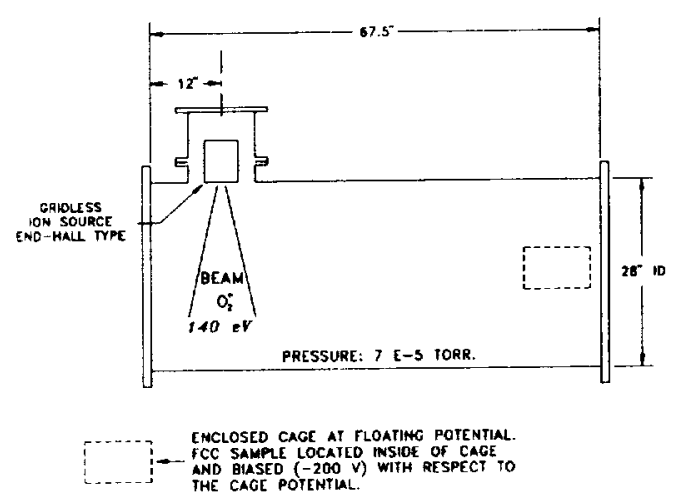

Figure 2: NASA LeRC's directed Atomic Oxygen Beam Facility.

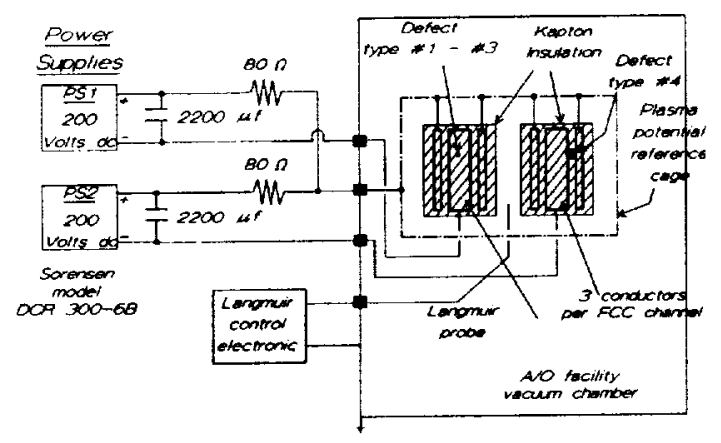

Figure 3: Negatively biased FCC with respect to plasma.

return line, exposing a supply and a return line to the plasma. The circuit of figure 3 does not have a closed current loop. Therefore, any current flow would be a result of the plasma interaction with the FCC. In the event that the plasma does initiate Kapton pyrolysis on the FCC, the ensuing short-circuit arc would complete the circuit. The 800 current-11miting resistor was employed to prevent the short-circuit current from going above 2.5 amps. The vacuum chamber was pumped down to $7 \times 10^{-5}$ corr. The output of the Sorensen power supplies was set at 200 volts dc. During these tests, no arcing was observed to occur on the FCC capable of causing the destructive arc tracking and propagation associated with Kapton pyrolysis. Furthermore, upon visual inspection of the samples, there appeared to be absolutely no damage to the FCC that could be attributed to the arcing.

\section{Localized Plasma}

The Abraded Circuit Experiments (ACE) test facility was utilized to determine the effects of a localized intense plasma generated at the defect site of an energized FCC. The ACE facility is a hellum-cryopumped bell jar capable of obtaining $5 \times 10^{-6}$ torr vacinm. The ACE facility has two types of power supplies to simulate the power from the proposed solar array panels for SSF. The first power supply is a Solar Array Simulator. The Solar Array Simulator, a constant current source utilizing an active feedback loop to maintain a constant current to the load (FCC), was designed to simulate the SSF solar array current transient responses (3). The current supplied to the FCC of the second source is voltage and resistance dependant, and has no feedback loop for current control; hence, it is referred to as the Quiescent Circuit Configuration.

Inductively Induced plasina. Due to the inductive component of the solar array panel, a localized plasma can be generated at the defect site if a microme teoroid or debris Impact severs a copper conductor. The Solar Array Simulator, electrically interfaced with the FCC as described in figure 4, was employed to create an inductively-induced, intense localized plasma at the defect site. Prior to the test, a supply line was intentionally severed

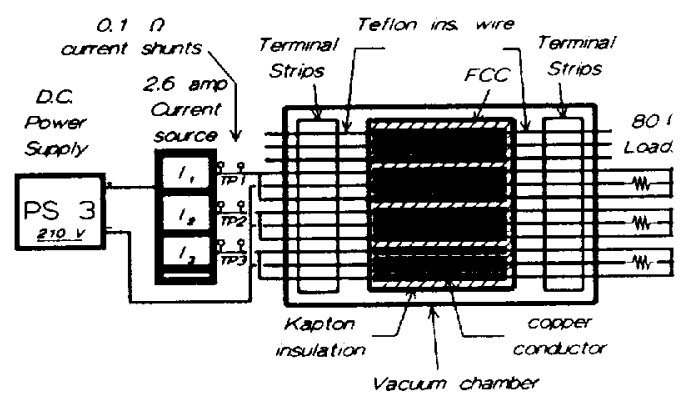

Figure 4: Solar Array Simulator circuit conflguration as used for testing Space Station Freedom's Flexible Current Carrier on the phenomena associated with Kapton pyrolysis, arc tracking, and propagation.

and repositioned back into place to allow current flow. Power was then applied to the FCC so that the repositioned severed supply line had 2.5 amps. Resistive loads were added to obtain a 160 -volt potential difference between conductors. After power was applied to the FCC, the supply line was reopened and a short-lived, bright blue arc appeared at the defect site. However, no Kapton pyrolysis event was detected.

Impact Plasma, An intense localized plasma could also be generated as a result of the kinetic energy associated with energetic micrometeoroid or debris impact. A similar plasma could be produced by discharging a capacitor at the defect site. The 
Quiescent Circuit Configuration described in figure 5 is a convenlent method to energize the FCC due to its simplistic design. The Quiescent Circuit Configuration was used to conduct this test along with a capacitor discharge to simulate the plasma caused by the particle Impact.

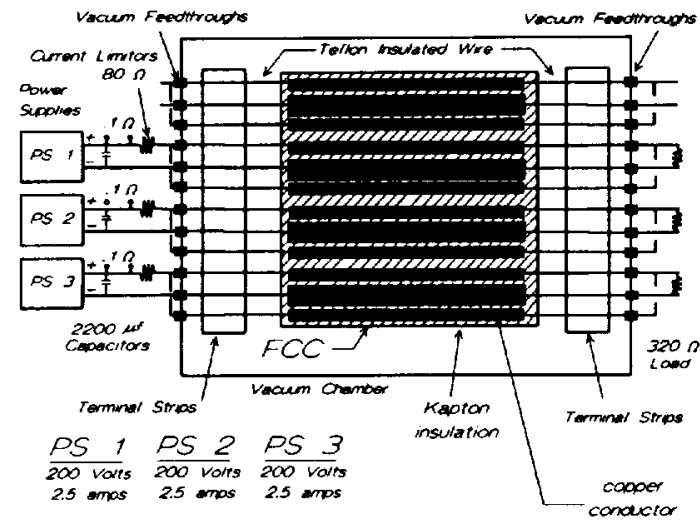

Figure 5: Quiescent Circuit Configuration as used for testing Space Station

Freedom's Flexible Current Carrier on the phenomena associated with Kapton pyrolysis, arc tracking, and propagation.

A $2200 \mu \mathrm{f}$ capacitor, not shown in figure 5, was charged up to predefined voltages and then discharged by contacting both capacitor leads with the exposed copper conductor at the defect site. With the capacitor charged up to 37 volts, the plasma energy generated with the capacitor discharge $\left(\mathrm{h}_{\mathrm{Cv}} \mathrm{v}^{2}\right)$ was approximately 1.51 Joules. However, no pyrolysis was experienced. With the capacitor charged up to 95 volts ( -10 Joules), the Kapton experienced some charring. Based on the assumption that maximum energy transfer would occur when the particle size is $20 x$ the thickness of the FCC, a particle with diameter $0.063 \mathrm{~mm}$ would result in the most intense plasma (4). The kinetic energy (KE) of the impacting particles 1s:

$$
K E=\frac{1}{2} m v^{2} \quad m=\rho \frac{4}{3} \pi r^{3}
$$

m - particle mass, $\rho$ - particle density $r$ - particle radius, $v$ - particle velocity

Therefore, a micrometeoroid or a debris particle of radius $0.0315 \mathrm{~mm}$ would have a kinetic energy of 0.0131 or 0.0096 Joules, respectively. This particle size has a flux of -10 particles $/\left(\mathrm{m}^{2}\right.$ year) (6). For a lifetime of 15 years, the number of $0.063 \mathrm{~mm}$-diameter particles expected would be $-150 / \mathrm{m}^{2}$. The surface area of the FCC is suffi. ciently large that numerous particle impacts of this size and energy will result. However, as previously noted, the plasma generated would have to be 1000 times greater than that expected from

\begin{tabular}{|c|c|c|}
\hline Particle: & $\begin{array}{c}\text { density } \\
\left(\mathrm{kg} / \mathrm{m}^{3}\right)\end{array}$ & $\begin{array}{c}\text { velocity } \\
(\mathrm{m} / \mathrm{sec})\end{array}$ \\
\hline $\begin{array}{c}\text { micro- } \\
\text { meteoroid }\end{array}$ & 500 & 20000 \\
\hline debris & 3000 & 7000 \\
\hline
\end{tabular}

Micrometeoroid and debris density and velocity ( 5 ).

particle impact, for the Kapton pyrolysis event to occur. Thus pyrolysis caused by micrometeoroid or debris impact is not expected to occur.

Short circuit. A momentary short circuit between a supply line and a return line may initiate Kapton pyrolysis. Conductors may become loose, as a result of micrometeoroid or debris impacts, coupled with atomic oxygen erosion, rendering them susceptible to free movement to come in contact with other conductors. The shorting event could also occur during extension and retraction exercises of a defective FCC. To simulate these conditions, the Quiescent Circuit Configuration of figure 5 was used. The local plasma was generated by short circuiting a supply and return line at a typical defect site with the use of a copper wand. The copper wand was designed so that with external manual control, the wand could be manipulated to make a momentary contact between the supply and return line. The current-limiting resistors were inserted to prevent the current from surpassing SSF current specifications. Therefore, when the power supplies are set at 200 volts, the max current would be 2.5 amps by Ohm's law, which is well below the SSF operation current of 5 amps. The load resistance was selected to be $320 \mathrm{ohms}$ so that, according to Kirchhoff's voltage law, when the power supplies are set at 200 volts, the potential difference between conductors will be 160 volts. However, with the power supplies set at only 180 volts ( 145 volts between conductors) the Kapton experienced pyrolysis.

\section{CONSEQUENCES OF KAPTON PYROLYSIS}

The Kapton pyrolysis tests mentioned above were conducted to determine whether the FCC could experience pyrolysis at SSF power levels. The following tests were conducted to project the extent of damage to the FCC if the Kapton pyrolysis event should occur. The arc tracking event is defined as Kapton pyrolysis initiated at a defect site on a channel which creates a conductive median between the supply and return lines, with arc migration down the chamel that depletes the Kapton insulation and destroys the copper conductors for that channel. Arc propagation, sometimes referred to as flash. over, results when the Kapton insulation of a 
channel becomes pyrolyzed due to the arc tracking event of a neighboring channel. The arc propagation occurrence could lead to total destruction of the FCC on SSF. For arc tracking tests, only one channel was energized at a time, whereas for propagation tests, three of the four channels were energized. For these tests, the two circuit configurations utflized were described in figure 4 and figure 5. The Solar Array Simulator described in figure 4 was employed to study the current requirements for Kapton pyrolysis, arc tracking, and propagation. The Quiescent Circuit of figure 5 was used to study the voltage requirements for Kapton pyrolysis, arc tracking, and propagation. For the following tests, the current flow through the FCC was monitored to ascertain whether the current transient response, due to the initiation of an arc, remained within operating specifications of SSF photovoltaic arrays. Current monitoring was done by either observing the voltage drop across a $0.1 \mathrm{ohm}$ dc current shunt, or with the use of a Tektronix current probe $\mathrm{A} 6303$ and amplifier AMS03.

Referring to the circuit of figure 4, the Solar Array Simulator was designed to provide a constant current supply and simulate the current transient response of the solar array panels. Each of the three channels on the Solar Array Simulator was capable of providing two amps. A suitable load of 80 ohms was added to facilitate the 160 volt potential difference between the supply and return lines when the Solar Array Simulator was operating at full power. All three Solar Array Simulator circuits operated from the same power supply, which was rated for 9 amps and set at 210 volts. The current level for each circult was manually adjustable with the use of a trimpot on the simulator control panel. The initial setup of the test had the current set at 0.5 amps, and the current was increased to two amps in 0.5 -amp increments. A shorting wand was manipulated over a typical defect site to create the momentary short circuit necessary to initiate Kapton pyrolysis after each increment in current. With the current level set at two amps, the momentary short circuit between conductors created by the shorting wand intiated a violent arc tracking event that had intense arcs on the FCC, coupled with molten copper sparks projecting from the FCC. The sparks are believed to be copper because small, round copper particles were found in a tray at the bottom of the vacuum bell jar. The arc tracking event continued until power was removed from the circuit. The current transient peaks during the pyrolysis occurrence were less than five amps. Therefore, the power in the FCC during the short circuit event never rose above the typical power that will be avallable on the FCC of SSF. After the arc tracking event, when power was applied to neighboring channels, additional arc tracking was initiated without the use of the shorting wand. Therefore, the pyrolysis event from the first channel pyrolized the Kapton on its neighboring channels. The neighboring channels did not experience arc tracking while the first channe 1 was arc tracking because power was only applied to the first channel. Furthermore, only 1.6 amps was necessary to start the arc tracking event on the neighboring channels. Therefore, the arc tracking event was found to need two amps to inftiate, and 1.6 amps to sustain. The arc tracking event could be stopped by removing power from the defective channel. However, the arc tracking event will restart when power is reapplied to the channel.

The voltage requirement necessary for arc tracking and propagation was derived using the quiescent circuit configuration of figure 5 . The current-limiting resistors were used so that during short-circult conditions, the current would be limited to the power supply voltage divided by the current limling resistor, $\mathrm{Ohm}^{\prime} \mathrm{s}$ law. For the circuit in figure 5 , the current would be limited to 2.5 amps when the power supplies are set at 200 volts. The load resistance was selected so that when the power supply is set for 200 volts by Kirchhoff's voltage laws, the potential difference between a supply line and a return line would be 160 volts. By adjusting the voltage of the power supplies, the potential difference between conductors on the FCC could also be controlled. Therefore, the quiescent circuit configuration of Figure 5 was comvenient for testing the threshold voltages necessary for Kapton arc tracking and propagation. The initial configuration of the test set the potential difference between conductors at 16 volts, and the voltage was increased in 20-volt increments. The shorting wand was manipulated over the defect site to create the momentary short circuit necessary to initiate Kapton pyrolysis after each increment in voltage. When the voltage was set at 140 volts, the arc tracking event started. The arc tracking was stopped by removing power from the FCC. However, only 90 volts was necessary to restart the arc tracking event when power was reapplied. It is belleved that the history of arcs created at the defect site for the lower voltage settings was a contributing factor to the arc tracking event initially occurring at 140 volts. In addition, the arc tracking event did not occur when the voltage was less than 140 volts. The current in the FCC with the voltage of 140 volts was less than 0.5 amps prior to short circuit, and 1 imited to 2.2 amps during the short circuit event. The typical power in the FCC of SSF will be 160 volts potential difference, and five amps of current. Therefore, these tests achleved arc tracking at voltage and current levels below SSF power levels. The arc propagation affected the neighboring channel's supply line, but the arc did not cross any return 1ines. The arc remained within the return lines of the two channels, and only the two channels were damaged. Since these tests were conducted at power levels below that at which the actual FCC of SSF will be operating, the higher power of SSF would be expected to propagate to more than one channel given the constant current source nature of the photovoltaic solax arrays.

\section{SUMMARY}

The LEO space plasma is not at risk to initiate Kapton pyrolysis on a defective FCC at SSF 
power levels. Furthermore, at SSF power levels, the probability of an inductively-induced plasma, generated at the epoch of a conductor opening. initiating Kapton pyrolysis, has been found to be very low. The event of a micrometeorold or debris impact initiating Kapton pyrolysis due to energy transformation from kinetic to plasma energy is also highly unlikely. However, a momentary short circuit did Initiate Kapton pyrolysis consistently at power levels below SSF operating power levels. It has been found that arc tracking and propagation will ensue once the pyrolysis begins. The power requirement to initiate the Kapton pyrolysis event, 140 volts and 2 amps, is higher than the power requirement necessary to maintain the arc tracking and propagation phenomenon. Furthermore, once the Kapton pyrolysis event has been introduced, if power was removed to stop 1t, minimal power is necessary to reinitiate the arc tracking event. The Kapton arc tracking event, once initiated, would proceed to destroy the channel of the FCC so long as power is applied to the damaged channel. If power is applied to any other channels of the FCC, the arc will propagate and destroy those channels also.

\section{Acknowledgement}

Research was supported by NASA Lewis Research Center's Space Station Freedom Directorate. The author would like to thank Bryan $K$ Smith and Marian C Felder of the NASA LeRC. Solar Array Branch, for their technical contributions.

\section{References}

1. Howard, J.F, and Mercado, M., "Potential Risk to Spacecraft by 'Kapton Flashover, " Materlals and Processes Engineering Report (0/62-92), June 24,1988 .

2. Howard, J.F, and Cady, E.M., "Supplemental Report on the Potential Risk to Spacecraft by "Kapton Flashover," SSD Reliability and Survivability Engineering Report (0/62-95), October $13,1989$.

3. Vasek, T.E. and Birchenough, A.G., "Development of a Ninety String Solar Array Simulator," $26^{\text {th }}$ Intersociety Energy Conversion Engineering Conference, Boston, Massachusetts, August 4-9, 1991 .

4. Zolensky, M.E. "Properties and Interactions of Interplanetary Dust," Proceedings of the $85^{\text {th }}$ Colloquium of the International Astronomical Union, Marse111e, France, July 9-12, 1984.

5. Kessler J, Donald, National Aeronautics and Space Administration, Lyndon B. Johnson Space Center, Personal Communication.

6. Space Station Program Natural Environment Definttion for Design, Change request SSP30425, January, 1991.

1. Work supported by contract NAS3-25266, Task Order 5428 .

2. Kapton is a registered trademark of E.I. du Pont de Nemours \& Co., Inc. 
Public reporing burden for this collection of information is estimated to average 1 hour per response, including the time for reviewing instructions, searching existing data sources, gathering and maintaining the data needed, and completing and reviewing the collection of information. Send comments regarding this burden estimate or any other aspect of this Operations and Report, 1215 Jefferson

\begin{tabular}{|c|c|c} 
1. AGENCY USE ONLY (Leave blank) & $\begin{array}{c}\text { 2. REPORT DATE } \\
\text { November } 1991\end{array}$ & $\begin{array}{c}\text { 3. REPORT TYPE AND DATES COVERED } \\
\text { Final Contractor Report }\end{array}$
\end{tabular}

4. TITLE AND SUBTITLE

Evaluation of Kapton Pyrolysis, Arc Tracking, and Arc Propagation on the

Space Station Freedom (SSF) Solar Array Flexible Current Carrier (FCC)

6. AUTHOR(S)

Thomas J. Stueber

\section{FUNDING NUMBERS}

WU- $474-46-10$

C-NAS3-25266

8. PERFORMING ORGANIZATION REPORT NUMBER

$E-6655$

Sverdrup Technology, Inc.

Lewis Research Center Group

2001 Aerospace Parkway

Brook Park, Ohio 44142

9. SPONSORING/MONITORING AGENCY NAMES(S) AND ADDRESS(ES)

National Aeronautics and Space Administration

Lewis Research Center

Cleveland, Ohio 44135-3191

NASA CR - 189056

11. SUPPLEMENTARY NOTES

Project Manager, Bruce A. Banks, Power Technology Division, NASA Lewis Research Center, (216) 433-2308. Prepared for the 22nd Photovoltaic Specialists Conference sponsored by the Institute of Electrical and Electronics Engineers, Las Vegas, Nevada, October 7 - 11, 1991.

12a. DISTRIBUTION/AVAILABILITY STATEMENT

12b. DISTRIBUTION CODE

Unclassified - Unlimited

Subject Category 23

13. ABSTAACT (Maximum 200 words)

Recent studies conducted by the Air Force Materials Laboratory and Lockheed Missiles and Space Company involving the use of polyimide Kapton ${ }^{2}$ coated wires indicate that if a momentary electrical short circuit occurs between two wires, sufficient heating of the Kapton can occur to thermally char (pyrolyze) the Kapton $(1,2)$. Such charred Kapton has sufficient electrical conductivity to create an arc which tracks down the wires and possibly propagates to adjoining wires. These studies prompted an investigation to ascertain the likelihood of the Kapton pyrolysis, arc tracking and propagation phenomena, and the magnitude of destruction conceivably inflicted on Space Station Freedom's (SSF) Flexible Current Carrier (FCC) for the photovoltaic array. The geometric layout of the FCC, having a planar-type orientation as opposed to bundles, may reduce the probability of sustaining an arc. An experimental investigation has been conducted to simulate conditions under which an arc can occur on the FCC of SSF, and the consequences of arc initiation.

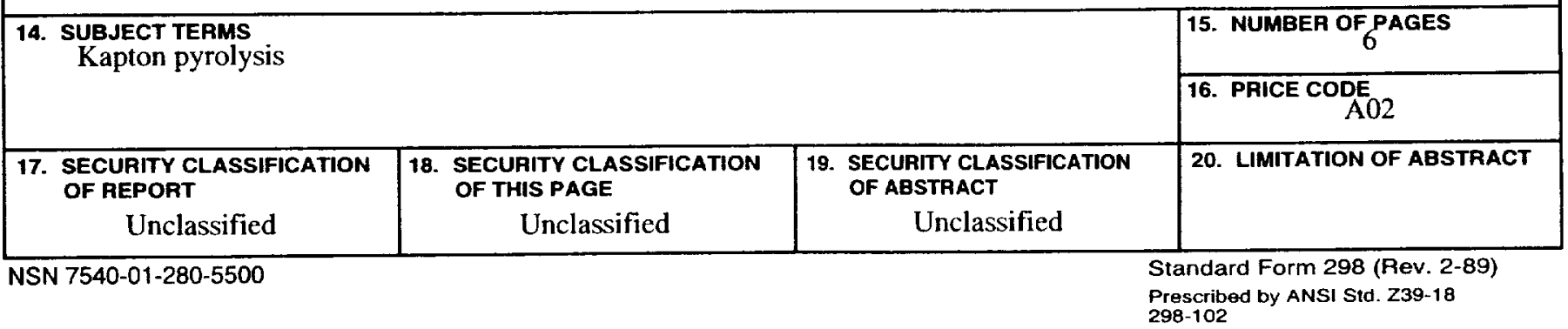

